\title{
GERAÇÕES FAMILIARES, HIERARQUIA E IMIGRAÇÃO PORTUGUESA NO BRASIL MERIDIONAL: ASPECTOS E FATORES DAS LIMITAÇÕES DAS OPORTUNIDADES SOCIAIS DE MEMBROS DA FAMÍLIA VIEIRA DOS SANTOS (VILAS DE MORRETES E PARANAGUÁ, PROVÍNCIA DE SÃO PAULO, 1812-1848)
}

Family generations, hierarchy and Portuguese immigration in Southern Brazil: aspects and factors of the limitations of social opportunities for members of the family Vieira dos Santos (Municipalities of Morretes and Paranaguá, Province of São Paulo, 1812-1848)

\author{
André Luiz Moscaleski Cavazzani* \\ Sandro Aramis Richter Gomes **
}

\begin{abstract}
RESUMO
Neste artigo é empreendido um estudo sobre os percursos sociais de quatro indivíduos da família Vieira dos Santos, os quais habitaram os municípios de Morretes e Paranaguá, localizados no litoral do atual Estado do Paraná, na primeira metade do século XIX. Na época, tais municípios pertenciam à jurisdição da Província de São Paulo. A principal finalidade deste artigo é evidenciar a natureza das dificuldades econômicas e das restrições de oportunidades sociais destes descendentes de imigrantes portugueses que se estabeleceram, a partir do fim do século XVIII, em áreas litorâneas do Brasil Meridional. Nesse âmbito, são sustentados três argumentos. Primeiro, é demonstrado que, no contexto do litoral sul paulista, as relações de crédito geravam indissolúveis vínculos de dependência. Tais vínculos eram transmitidos de uma geração para outra. Segundo,

\footnotetext{
* Professor do Centro Universitário Uninter. Mestre em História pela UFPR, doutor em História pela USP. Realizou estágio pós-doutoral na UFPR

** Mestre em História pela UFPR e Doutorando em História pela UFPR.
} 
argumenta-se que a realização de migrações internas foi uma prática presente entre os portugueses - e seus descendentes menos abastados. As migrações eram uma consequência de eventos como a falência comercial ou a iniciação em um novo ramo da vida mercantil. Terceiro, é evidenciado que, no litoral sul paulista, os pequenos comerciantes de origem portuguesa não tiveram acesso ao mercado matrimonial composto pelos seus compatrícios enriquecidos. Em síntese, a partir desse caso, demonstra-se que as distâncias econômicas entre os membros da comunidade de imigrantes portugueses implicavam restrições à formação de laços familiares entre eles. Nesse quadro, trata-se de demonstrar que os portugueses que constituíram relações familiares com os Vieira dos Santos eram pequenos comerciantes que compunham os séquitos de credores dos portugueses enriquecidos de Morretes e Paranaguá. As fontes utilizadas para a análise são os textos memorialísticos Breve resumo das memórias mais notáveis acontecidas desde 1797 até 1827 e Memórias dos sucessos mais notáveis acontecidos desde o ano de 1838 de Antonio Vieira dos Santos.

Palavras-chave: Brasil Meridional; hierarquias sociais; imigração portuguesa.

\begin{abstract}
This article is a study undertaken on trajectories of four individuals of Vieira dos Santos family, lived in the cities of Morretes and Paranaguá, located on the coast of current state of Paraná, in the first half of the nineteenth century. At the time, the municipalities belonged to the jurisdiction of the Province of São Paulo. The main purpose of this article is to highlight the nature of the economic difficulties and constraints of social opportunities descendants of Portuguese immigrants who settled from late eighteenth century, in coastal areas of Southern Brazil. In this context, they are held three arguments. First, it is show that, in this context of south coastal of Province of São Paulo, credit relations generated indissoluble dependency links. Such bonds were transmitted from one generation to another. Second, it is argued that the realization of internal migration was a practice of the Portuguese - and their descendants - less affluent. Migrations were a result of events such as business failure or trying to start a new branch of business life. Third, it is evident in Southern Brazil small merchants from Portugal did not participate in the marriage market made by their countrymen enriched. In summary, the economic distance between the members of the Portuguese immigrant community implied restrictions on the formation of family ties between them. In this context, it is demonstrate that the immigrants who remained family relationships with the Vieira dos Santos were small traders who made up the entourage of creditors of enriched Portuguese.
\end{abstract}

Keywords: Portuguese immigration; social hierarchies; Southern Brazil 


\section{Introdução}

Este artigo comporta uma investigação acerca da natureza e das origens das limitações das oportunidades sociais de uma família de origem portuguesa cujos membros habitaram os municípios de Morretes e Paranaguá, situados no litoral do atual Estado do Paraná, na primeira metade do século XIX. Os integrantes dessa família - os Vieira dos Santos - dedicavam-se ao comércio varejista e à negociação de erva-mate. ${ }^{1} \mathrm{O}$ objetivo central deste estudo é demonstrar o caráter hierarquizado das relações sociais mantidas entre os membros da comunidade étnica portuguesa formada no litoral sul da Província de São Paulo. Os referidos municípios pertenceram à jurisdição dessa província até o ano de 1853, quando foi criada Província do Paraná. As fontes empregadas na execução desse estudo são os dois textos memorialísticos de autoria do imigrante português Antônio Vieira dos Santos. Esses textos são intitulados Breve resumo das memórias mais notáveis acontecidas desde 1797 até 1827 e Memórias dos sucessos mais notáveis acontecidos desde o ano de $1838^{2}$

Nesse quadro, compete evidenciar que o estudo do modo de funcionamento do mercado matrimonial e do mercado de crédito naquela região propicia o conhecimento sobre as formas de dependência e dominação social que existiram entre os componentes da aludida comunidade. Ao mesmo tempo, a execução desta abordagem permite a compreensão sobre as consequências sociais das restrições de oportunidades econômicas de integrantes dessa comunidade. Uma consequência era a realização de migrações

1 Os componentes da família Vieira dos Santos que têm as suas trajetórias estudadas no presente artigo são o imigrante português Antônio Vieira dos Santos (1784-1854) e os seus filhos Antônio Vieira dos Santos Júnior (1805-?), Ana Joaquina de Oliveira França (1811-?) e José Vieira dos Santos (1813-1850). Antônio Vieira dos Santos também foi pai de José, que faleceu em 1807, uma semana após o nascimento e de Maria Cândida (1808-?), que permanecia solteira em 1851, época da conclusão da escrita das memórias de Antônio Vieira. Dessa forma, o arrolamento de membros da família Vieira dos Santos seguiu o critério de selecionar apenas os integrantes que desenvolveram atividades econômicas e que se envolveram no mercado matrimonial que funcionava na região litorânea do atual Estado do Paraná.

2 Ambos os textos estão sob a guarda do Círculo de Estudos Bandeirantes (Curitiba, Rua XV de Novembro, 1050). 
internas pelos comerciantes não enriquecidos. Assim, compete salientar as estratégias sociais e econômicas empregadas por portugueses que experimentaram reveses em suas atividades econômicas. Outra consequência era a limitação das formas de interação entre os abastados e os pequenos negociantes. Nesse âmbito, o presente estudo objetiva evidenciar as distâncias sociais que existiram aos membros daquela comunidade.

O presente artigo é desenvolvido em três estágios. Primeiro, é elaborado o estudo sobre o envolvimento de membros de duas gerações da família Vieira dos Santos no mercado de crédito controlado por negociantes portugueses radicados em Morretes e Paranaguá. Nesse sentido, é salientado que os pequenos comerciantes que pertenciam a essa parentela permaneceram durante décadas dependentes dos empréstimos fornecidos por abastados negociantes portugueses. A obtenção de crédito era crucial para que os pequenos comerciantes pudessem recomeçar ou diversificar a sua atividade mercantil. A dependência pelos créditos fornecidos por tais negociantes foi peculiar, portanto, a duas gerações da família Vieira dos Santos.

No segundo estágio desta investigação compete evidenciar que a realização de migrações internas apresentou-se como uma alternativa a duas gerações de membros da família Vieira dos Santos. Por um lado, essas migrações eram realizadas em contextos de aprofundamentos das adversidades econômicas vivenciadas por tal parentela. Por outro lado, tais migrações não tiveram efeitos econômicos positivos. Assim, demonstra-se que a transferência para sociedades do primeiro planalto do atual Estado do Paraná foi efêmera. O retorno ao litoral foi, pois, o destino peculiar a duas gerações de integrantes dessas famílias.

No terceiro estágio desta abordagem é evidenciado que, em meados dos séculos XIX, a escolha dos padrinhos dos filhos dos membros da família Vieira dos Santos assumiu um caráter endógeno. Dessa maneira, os próprios integrantes dessa parentela eram os compadres de seus familiares. Nesse contexto, os abastados negociantes portugueses não integravam o rol dos compadres dos Vieira dos Santos. A proximidade entre os abastados e modestos negociantes de origem portuguesa, na mencionada região, foi circunscrita à primeira década do século XIX. Em síntese, era vedada 
a inserção de pequenos comerciantes de origem portuguesa no mercado matrimonial e nas relações de compadrio dos portugueses economicamente mais poderosos. Nessa época, os Vieira dos Santos constituíam relações familiares com indivíduos que se enquadravam na qualidade de pequenos comerciantes portugueses que também dependiam dos créditos dos abastados negociantes.

Em resumo, o estudo desenvolvido nesta etapa da análise permite evidenciar que, nas referidas sociedades litorâneas, os pequenos comerciantes portugueses formavam uma comunidade na qual eram realizadas alianças familiares e econômicas. Compete, assim, destacar a vigência de rígida estratificação social entre os membros da comunidade étnica portuguesa na citada região.

$* * *$

A historiografia atinente à imigração de europeus para o Brasil Meridional avançou na compreensão do comportamento demográfico de distintas comunidades étnicas no decorrer dos séculos XIX e XX. Dessa forma, tal vertente de análise contribuiu para a produção de um conhecimento sobre os fatores das mudanças, por exemplo, nas taxas de natalidade e nos padrões de nupcialidade dessas comunidades. Em resumo, o estudo sobre os padrões de comportamento demográfico possibilitou o entendimento a respeito do ritmo de integração de membros das comunidades étnicas em sociedades localizadas ao Sul do Brasil. A partir dos anos 1970, o estudo sobre padrões demográficos de comunidades étnicas do Sul do Brasil obtiveram especial desenvolvimento. Por conseguinte, foram elaboradas investigações acerca da imigração, para a Província do Paraná, de grupos tais como os alemães, italianos, ucranianos e poloneses. $^{3}$

3 A esse respeito, compete atentar aos seguintes estudos que fazem parte da gênese das investigações em demografia histórica no Brasil: BALHANA, Altiva Pilatti. Santa Felicidade. Uma paróquia Veneta no Brasil. Curitiba: Fundação Cultural, 1978; HOBARTIUK, Paulo. Imigração 
Contudo, o avanço nos estudos sobre comunidades étnicas não chegou a propiciar o conhecimento sobre as diferenças sociais internas aos membros dessas etnias. Por conseguinte, a ênfase no estudo do comportamento demográfico não foi acompanhada pelo reconhecimento das origens e implicações sociais da diferenciação econômica entre os componentes dessas comunidades. Assim, os estudos que acompanharam os padrões demográficos de descendentes de imigrantes em distintos contextos históricos não atentaram para as desigualdades internas aos integrantes de comunidades étnicas. ${ }^{4}$

Referente aos estudos de história da imigração no Brasil Meridional cabe ressaltar que abordagens sobre trajetórias individuais possibilitaram a compreensão acerca das condições de integração de imigrantes na sociedade receptora. ${ }^{5}$ Tais estudos permitiram, também, a compreensão sobre a natureza das iniciativas econômicas e da mobilidade social de integrantes dessas comunidades. ${ }^{6}$ Em síntese, a

ucraniana no Paraná. União da Vitória: Fundação Faculdade de Filosofia, Ciências e Letras de União da Vitória, 1989; NADALIN, Sergio Odilon. A Origem dos noivos nos registros de casamentos da Comunidade Evangélica Luterana de Curitiba. Dissertação (Mestrado em História). Curitiba: Universidade Federal do Paraná, 1974; NADALIN, Sergio Odilon. Une paroisse germanique au Brésil: la communauté évangélique luthérienne à Curitiba entre 1866 et 1969. Tese (Doutorado em História e Geografia das Populações). Paris: École des Hautes Études em Sciences Sociales, 1978; RANZI, Serlei Fischer. Alemães católicos em Curitiba: aspectos sociodemográficos (1850-1919). Dissertação (Mestrado em História). Curitiba: Universidade Federal do Paraná, 1983; WACHOWICZ, Ruy Cristovam. Abranches: paróquia da imigração polonesa. Dissertação (Mestrado em História). Curitiba: Universidade Federal do Paraná, 1974.

4 Concernente aos estudos que abordam o tema da formação de comunidades étnicas em perspectiva de longa duração convém salientar a análise de Cacilda Machado sobre uma família alemã radicada no município paranaense de Curitiba em meados do século XIX. Ver MACHADO, Cacilda da Silva. De uma família imigrante: sociabilidades e laços de parentesco (1854-1991). Dissertação (Mestrado em História). Curitiba: Universidade Federal do Paraná, 1994. Acerca, por seu turno, de abordagem de longa duração que discorre sobre a formação de comunidade ucraniana no interior do Estado do Paraná no fim do século XIX, ver ANDREAZZA, Maria Luiza. Paraíso das delícias: estudo de um grupo imigrante ucraniano (1895-1995). Tese (Doutorado em História). Curitiba: Universidade Federal do Paraná, 1996.

5 Nesse quadro, compete mencionar o estudo de Beatriz Pellizzetti sobre a trajetória de um imigrante italiano na região do Vale do Itajaí, na Província de Santa Catarina. Ver PELliZZETTI, Beatriz. Pioneirismo italiano no Brasil Meridional: estudo de caso. Curitiba: Instituto Histórico, Geográfico e Etnográfico Paranaense, 1981.

6 Trata-se de mencionar, pois, o estudo de João Baptista Penna de Carvalho Neto sobre o empresário alemão Floriano Essenfelder, que se radicou em Curitiba na segunda metade do século XIX. Ver CARVALHO NETO, João Baptista Penna de. Floriano Essenfelder: a trajetória de um empresário. Dissertação (Mestrado em História). Curitiba: Universidade Federal do Paraná, 1992. De outra parte, compete destacar a análise de Beatriz Pellizzetti atinente a uma iniciativa econômica de membros da comunidade italiana estabelecidos em Santa Catarina, no contexto das primeiras décadas do século XX. 
história sobre as comunidades étnicas no Sul do Brasil permanece carente de análises sobre os fatores que engendravam a hierarquização entre imigrantes, bem como entre os seus descendentes. Dessa maneira, a historiografia sobre a atuação social e econômica dos imigrantes na citada região não conferiu expressiva ênfase ao tema da reiteração das desigualdades entre compatrícios.

De outra parte, compete salientar que os estudos sobre imigração concentram-se no período posterior à segunda metade do século XIX. Ou seja, as análises estão centradas na época de impulso transferência de europeia para o Brasil em decorrência da política de atração de imigrantes do Governo Imperial. Nesse âmbito, o estudo da imigração de portugueses para o Brasil anteriormente a este contexto mereceu pouca ênfase da historiografia. As análises concernentes a tal processo imigratório, por um lado, ocupam-se da compreensão dos padrões demográficos e das condições de inserção de portugueses e ilhéus no Brasil a partir do século XVIII. ${ }^{7}$ Assim, encontra-se em estágio inicial a compreensão sobre a inserção de portugueses e ilhéus na hierarquia social de áreas do Brasil Meridional em época anterior ao desenvolvimento de uma política de Estado voltada à atração de imigrantes. ${ }^{8}$ Por conseguinte, a abordagem empreendida neste artigo permite um conhecimento acerca dos impactos da hierarquização interna a uma comunidade étnica nas condições de ampliação de vínculos familiares e na obtenção de oportunidades para a diversificação de práticas econômicas. Em resumo, compete demonstrar as características das desigualdades internas a uma comunidade étnica e seus efeitos na dinâmica econômica e social de área litorânea do Brasil Meridional.

Tal iniciativa consistiu na fundação de um banco, em 1928. PELLIZZETTI, Beatriz. Um banco de imigrantes em Santa Catarina. Blumenau: Fundação "Casa Dr. Blumenau”, 1985.

7 BARROSO, Vera Lúcia Maciel. Açorianos no Brasil. Porto Alegre: EST, 2002; QUEIROZ, Maria Luiza Bertulini. Paróquia de São Pedro do Rio Grande: estudo de história demográfica (1737-1850). Tese (Doutorado em História). Curitiba: Universidade Federal do Paraná, 1992; SCOTT, Ana Volpi (Org.). Gente das Ilhas: trajetórias transatlânticas dos Açores ao Rio Grande de São Pedro entre as décadas de 1740 e 1790. São Leopoldo: Oikos, 2014.

8 A esse respeito, ver HAMEISTER, Martha Daisson. Para dar calor à nova povoação: estratégias sociais e familiares a partir dos registros batismais da Vila do Rio Grande (c.1748c.1763). Tese (Doutorado em História Social). Rio de Janeiro: Universidade Federal do Rio de Janeiro, 2006; MARQUES, Rachel dos Santos. Por cima da carne seca: hierarquia e estratégias sociais no Rio Grande do Sul (c.1750-1820). Curitiba: Universidade Federal do Paraná, 2012. 
De outra parte, o estudo realizado neste artigo propicia o entendimento sobre a natureza das atividades econômicas de pequenos e abastados negociantes de área provincial. Presentemente, os estudos sobre as relações de crédito e as operações mercantis de grandes negociantes são desenvolvidos com especial ênfase para o caso da capital do Império. ${ }^{9}$ Assim, permanece pouco desenvolvido o estudo sobre a hierarquização social e o funcionamento da economia na região na qual estavam fixados os membros da família Vieira dos Santos - o litoral sul da Província de São Paulo. ${ }^{10}$ A consecução deste artigo, portanto, propicia o conhecimento sobre as diferenças sociais e econômicas que vigoraram em duas sociedades interioranas do Sul do Brasil no contexto que abarca a formação do Estado Imperial.

\section{Imigrantes portugueses, mercado de crédito $e$ dependência econômica: Antônio Vieira dos Santos e seus filhos Antônio e José}

Nesta seção é demonstrado que, no âmbito litoral sul da Província de São Paulo, os pequenos comerciantes mantinham duradouros vínculos de dependência econômica com os abastados negociantes de origem portuguesa. Esses vínculos eram uma decorrência da busca por empréstimos necessários ao financiamento de iniciativas como a entrada em um determinado ramo do comércio

9 SAMPAIO, Antônio C. Jucá de. Os homens de negócio do Rio de Janeiro e sua atuação nos quadros do Império Português (1701-1750). In: FRAGOSO, João; BICALHO, Maria Fernanda; GOUVÊA, Maria de Fátima (Orgs.). O antigo regime nos trópicos: A dinâmica imperial portuguesa (séculos XVI-XVIII). Rio de Janeiro: Civilização Brasileira, 2001, p.73-105; FLORENTINO, Manolo \& FRAGOSO, João. O Arcaísmo como Projeto: Mercado atlântico, sociedade agrária e elite mercantil em uma economia colonial tardia. Rio de Janeiro, c. 1790 - c. 1840. Rio de Janeiro: Civilização Brasileira, 2001.

10 A esse respeito, ver CAVAZZANI, André. Tendo o sol por testemunha: população portuguesa na Baía de Paranaguá (c. 1750-1830). Tese (Doutorado em História Social). São Paulo: Universidade de São Paulo, 2013; LEANDRO, José Augusto. Gentes do grande mar redondo: riqueza e pobreza na Comarca de Paranaguá (1850-1888). Tese (Doutorado em História). Florianópolis: Universidade Federal de Santa Catarina, 2003. 
ou a diversificação dos negócios. A ausência de alternativas de financiamento dessas iniciativas era um fator crucial para a manutenção dos citados vínculos. De outra parte, cumpre evidenciar que a dependência em relação aos negociantes portugueses poderia atravessar gerações. $\mathrm{O}$ estudo dos percursos sociais de membros da família Vieira dos Santos permite salientar a coexistência de duas gerações de uma mesma parentela sob o domínio econômico dos controladores do mercado de crédito da mencionada região.

Proveniente da cidade portuguesa do Porto, Antônio Vieira dos Santos transferiu-se para o Brasil em 1797. Após breve estada no Rio de Janeiro, fixou-se na vila de Paranaguá em 1798. No decorrer dos anos 1800, ele atuou como comerciante varejista nesta localidade. Mais precisamente, ele era o proprietário de um armazém de secos e molhados. ${ }^{11}$ Foi, pois, na década de 1810 que ocorreu a consolidação a dependência de Antônio Vieira para com os créditos fornecidos por negociantes radicados em Morretes e Paranaguá.

A demanda por esses créditos tornou-se mais frequente após Antônio Vieira se estabelecer em Morretes, em 1814. A falência comercial que ele experimentara em Paranaguá, no anterior, fora um fator decisivo para tal migração. Assim, a sua reabilitação como comerciante autônomo em outra sociedade dependeu tanto dos créditos fornecidos por comerciantes locais quanto da obtenção de crédito no Rio de Janeiro. ${ }^{12}$ Trata-se, portanto, de evidenciar as

11 Antônio Vieira dos Santos contraiu matrimônio, em 1804, com Maria Ferreira de Oliveira (1787-1840). Ela era sobrinha do imigrante açoriano Francisco Ferreira de Oliveira, antigo patrão de Antônio Vieira. Portanto, tal informação consiste em um indício de que a incorporação a uma família de imigrantes de Portugal ou das ilhas atlânticas era operacional para imigrantes recémchegados obterem suas primeiras oportunidades sociais e econômicas no litoral sul paulista, no contexto do fim do século XVIII e início do século XIX. Acerca das informações sobre a trajetória de Antônio Vieira, ver COSTA, Samuel Guimarães. O último capitão-mor (1782-1857). Curitiba: Editora da Universidade Federal do Paraná, 1988.

12 A historiografia tem demonstrado que, desde o período colonial, a demanda por crédito privado propiciava a formação de extensas redes de relações entre comerciantes de distintas capitanias e províncias do Brasil. Dessa forma, comerciantes de vilas interioranas mantinham vínculos, em decorrência do contrato de empréstimo, com negociantes economicamente mais poderosos de diferentes municípios. A esse respeito, ver BORGES, Joacir Navarro \& PEREIRA, Magnus Roberto de Mello. Tudo consiste em dívidas, em créditos e em contas: relações de crédito no Brasil colônia; Curitiba na primeira metade do século XVIII. In: Revista de História, São Paulo, n. $162,1^{\circ}$ Semestre de 2010, pp. 106-129; FARIA, Sheila de Castro. A colônia em movimento. Rio de Janeiro: Nova Fronteira, 1998. 
circunstâncias nas quais Antônio Vieira solicitou os seus primeiros empréstimos.

Em 1817, esse comerciante já mantinha um vínculo de dependência econômica para com o imigrante português Antônio José de Araújo (1791-1851), que residia em Morretes. Em verdade, esses imigrantes eram concunhados, visto que Araújo era esposo da irmã de Maria Ferreira de Oliveira. Assim, um aspecto comum às trajetórias de ambos os imigrantes consistiu em integrarem-se, em seus primeiros anos no Brasil, a uma família de imigrantes portugueses, a saber, os Ferreira de Oliveira. Tais informações consistem, pois, em evidências dos expressivos desníveis econômicos entre comerciantes portugueses ligados por vínculos familiares, no contexto das sociedades litorâneas de Morretes e Paranaguá da primeira metade do século XIX.

Nessa época, os créditos fornecidos por Araújo eram necessários para Antônio Vieira reabilitar-se como comerciante autônomo. Contudo, este indivíduo manifestou em suas memórias dificuldades para quitar as dívidas com seus compatriotas. Dessa maneira, cabe salientar um excerto das memórias de Antônio Vieira no qual há uma alusão a suas relações econômicas com Araújo: "Em 22 de Abril [de 1817] Terça $\mathrm{f}^{\mathrm{a}}$ andei bem triste e aflicto $\mathrm{p}^{\mathrm{r}}$ razão do meu Cunhado $\operatorname{Ar}^{\circ}$ querer que eu escrevese a $\mathrm{m}^{\mathrm{a}}$ divida no seu livro rubricado". ${ }^{13}$

Ao mesmo tempo, negociantes mais abastados de Morretes e Paranaguá também exerciam a função de intermediários nas relações entre o pequeno comerciante e os negociantes de praças mercantis como o Rio de Janeiro. Tais negociantes concediam empréstimos, portanto, a comerciantes estabelecidos em distintas províncias. Respeitante a tal intermediação, Antônio Vieira salientou que era Araújo quem recebia as cartas de cobrança da dívida que ele, Vieira, contraíra com um negociante do Rio de Janeiro, José Francisco de Mesquita.

Em 1814, no princípio da atuação de Vieira como comerciante em Morretes, já vigorava a sua dependência pelos

13 SANTOS, Antônio Vieira dos. Breve resumo das memórias mais notáveis acontecidas desde 1797 até 1838 [manuscrito], p. 26. 
empréstimos de José de Mesquita. Acerca desses empréstimos, Antônio Vieira informou: "Em 11 de $9^{\text {bro }}$ [de1814] Sesta fa recebeo meu cunhado $\mathrm{Ar}^{\circ}$ as cartas de Mesq ${ }^{\text {ta }}$ do Rio a resp ${ }^{\text {to }}$ da $\mathrm{m}^{\mathrm{a}}$ divida". ${ }^{14}$ Nesse quadro, nota-se que não havia um contato direto entre o pequeno comerciante de área interiorana de uma província e o seu credor estabelecido em importante praça mercantil.

Nesse quadro, Antônio Vieira dos Santos demandava a Araújo realizar o pagamento das dívidas que ele, Vieira, tinha com negociantes cariocas. A transcrição do seguinte excerto das reminiscências de Antônio Vieira possibilita destacar que, no Rio de Janeiro, ele não era devedor apenas de José de Mesquita: "12 de novembro de 1826] De m. falei com meu cunhado $\operatorname{Ar}^{\circ} \mathrm{p}^{\mathrm{a}} \mathrm{q}^{\prime}$ mandase pagar no Rio a $\mathrm{m}^{\mathrm{a}}$ divida ao A. F. $\mathrm{Al}^{\mathrm{s}}$ mostrando-lhe as Cartas q' do $\mathrm{m}^{\mathrm{mo}}$ tinha a este respt ${ }^{\circ}$ o q' prometeo fazer". ${ }^{15}$

A obtenção e a renegociação de empréstimos tornou-se um elemento peculiar tanto à trajetória de Antônio Vieira quanto às trajetórias de seus filhos. Assim, cumpre mencionar que, em 1814, após o recebimento de um aviso de cobrança, Vieira demandou o auxílio de sua sogra Ana Gonçalves Cordeiro e de seu concunhado Antônio de Araújo para renegociar a dívida. Essa renegociação implicou a manutenção, por vários anos, do vínculo de dependência econômica entre Vieira e José de Mesquita. Respeitante a essa renegociação, Vieira registrou que "Em 25 de $9{ }^{\text {bro }}$ Sesta $\mathrm{f}^{\mathrm{a}}$ pasei um credito ao Mesq ${ }^{\text {ta }}$ de q' lhe devia $p^{r}$ tempo de 6 annos de q' $m^{\text {a }}$ Sogra e meu Cunhado forão fiadores". ${ }^{16}$

Transcorridos os seis anos previstos para o pagamento da dívida, Vieira viajou para a cidade do Rio de Janeiro com a finalidade de conseguir renegociar o débito. $\mathrm{O}$ memorialista não informou $\mathrm{o}$ resultado da renegociação. Antes, destacou apenas a dificuldade para estabelecer contato com o seu credor:

Em 7 de Junho [de 1820] Quarta fr $^{\mathrm{a}}$ de manhã emtreguei hua carta ao Mesq ${ }^{\text {ta }}$ narrando-lhe os meus sentimentos $\mathrm{p}^{\mathrm{r}}$

14 Ibid., p. 21.

15 Ibid., p. 59.

16 Ibid., p. 21. 
não poder falar com elle nos dias 9-10-12-15 e 17 de Maio já de manhã de tarde e noite e só falei com elle em 24 de Maio Quarta fr $^{\mathrm{a}}$ e não pude falar em 26 e 30 do $\mathrm{m}^{\mathrm{mo}}$ mez, e nos dias 3-4-5 e 6 de Junho; e em 8 de Junho Quinta $\mathrm{fr}^{\mathrm{a}}$ fui falar com o Mesq ${ }^{\text {ta }}$ na Salla em cima e me dice estava $\mathrm{m}^{\text {to }}$ ocupado. [...] Em 15 de Junho Quinta $\mathrm{f}^{\mathrm{a}}$ de manhã fui a bordo do Bergantim. De tarde falei com o Mesq $^{\text {ta }}$ junto com meu cunhado a resp ${ }^{\text {to }}$ de q' lhe devia. De noite depois das 8 horas nos embarcamos na $\mathrm{Ci}^{\mathrm{de}}$ do Rio de Janeiro para bordo do Berg ${ }^{\text {am }}$ S. $\mathrm{M}^{\mathrm{el}}$ Imperador. ${ }^{17}$

Nessa viagem ao Rio de Janeiro, Antônio Vieira dos Santos obteve o dinheiro de um empréstimo concedido por imigrante português radicado em Paranaguá - Manuel Francisco Correia (17761864). Trata-se, de um indivíduo que, durante anos, manteve Antônio Vieira dos Santos e um filho deste imigrante na condição de membros do seu séquito de devedores. Acerca da concessão desse empréstimo, Vieira ressaltou: "Em 14 de Março Quarta fa me deu ordem o Sarg ${ }^{\text {to }}$ Mor $\mathrm{M}^{\mathrm{el}}$ Fran $^{\mathrm{co}} \operatorname{Corr}^{\mathrm{a}} \mathrm{p}^{\mathrm{a}}$ me darem no Rio os $400 \$ \mathrm{mil} \mathrm{r}^{\mathrm{s}}$ e se apromptarão os despachos; e me andei despedindo nos dias 15 e 16 ". ${ }^{18}$

José de Mesquita faleceu em 1822. Contudo, Vieira dos Santos continuou a receber cartas de cobranças pelas dívidas contraídas com o extinto negociante. A atenção a tais cobranças permite corroborar o argumento de que negociantes portugueses de Paranaguá intermediavam a cobrança de dívidas assumidas com membros da elite mercantil da cidade do Rio de Janeiro.

Em 1822, o português Manuel Antônio Pereira (1782-1857), que era na época capitão-mor de Paranaguá, informou Vieira dos Santos sobre a cobrança de um débito: "Em 23 de Fevr ${ }^{\circ}$ Dom $^{\circ} \mathrm{r}^{\text {ce }}$ cartas do $\mathrm{Cap}^{\mathrm{m}}$ Mor $\mathrm{M}^{\mathrm{el}} \mathrm{Ant}^{\mathrm{o}} \mathrm{Per}^{\mathrm{a}}$ em data de 19 pedindo-me a divida q' estava devendo ao Mesq ${ }^{\text {ta }}$ e respondi em $24 \mathrm{a} \mathrm{m}^{\mathrm{ma}}$ e andei todo este dia bem triste em consideraçõens sobre a ma vida". ${ }^{19}$ Tal informação 
evidencia que, na década de 1820 , já se consolidara, no litoral do atual Estado do Paraná, o desnível econômico entre portugueses que se transferiram para o Brasil na segunda metade do século XVIII. Conforme evidenciado neste artigo, esse desnível impunha barreiras para o estabelecimento de relações familiares entre os compatrícios.

A dependência de Antônio Vieira dos Santos e de seus filhos para com os auxílios econômicos de negociantes de origem portuguesa não se restringia à obtenção de empréstimos. Tal dependência verificava-se também nas oportunidades profissionais concedidas a eles, os Vieira dos Santos, pelos abastados negociantes de Morretes e Paranaguá. A análise dos textos memorialísticos de Antônio Vieira dos Santos demonstra que o seu filho primogênito, Antônio Júnior, atuou como caixeiro do citado português Antônio José de Araújo.

Em síntese, aos 17 anos de idade o filho de Antônio Vieira principiou a sua atividade na vida comercial na condição de subalterno de um português que, uma década após seu estabelecimento no Brasil, já dispunha dos recursos suficientes para atuar como fornecedor de crédito na sociedade de Morretes. Acerca do episódio da absorção de Antônio Júnior à categoria de empregado de Araújo, o memorialista ressaltou: "Em 6 de Dezembro Sesta de manhã foi meu $\mathrm{f}^{\mathrm{o}}$ Antonio $\mathrm{p}^{\mathrm{a}}$ Caix ${ }^{\mathrm{ro}}$ do meu cunhado $\mathrm{Ar}^{\mathrm{o}}$ pois ele $\mathrm{m}^{\mathrm{mo}}$ falou nisto a m ${ }^{\mathrm{a}}$ Sogra". ${ }^{20}$ Nos anos 1840, o agravamento das dificuldades econômicas impeliu Antônio Vieira, pai, a atuar como empregado de Araújo. Contudo, em 1819 ele já considerava a possibilidade de prestar serviços ao seu concunhado e patrício. Essa prestação de serviços consistiria, por exemplo, na intermediação de venda de mercadorias na então Capitania de Santa Catarina:

Em 8 de Janr $^{\circ}$ de 1819 Sesta $^{\text {a }}$ falou a $\mathrm{m}^{\text {er }}$ com meu cunhado $\mathrm{Ar}^{\mathrm{o}} \mathrm{p}^{\mathrm{a}}$ me mandar com carregaçõens $\mathrm{p}^{\mathrm{a}}$ a Ilha de

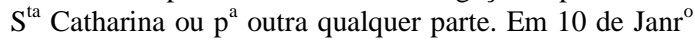
Dom $^{\circ}$ me offereceo meu cunhado $\mathrm{p}^{\mathrm{a}}$ me dar Carregaçõens. Em 16 de Janeiro Sabado falei 
dezenganadam ${ }^{\text {te }}$ a meu cunhado $\operatorname{Ar}^{\circ} \mathrm{p}^{\mathrm{a}} \mathrm{q}^{\prime}$ me ajudase sobre as $\mathrm{m}^{\text {as }}$ viagens maritimas. ${ }^{21}$

O estudo dos textos memorialísticos de Antônio Vieira dos Santos permite ressaltar que houve dois destinos mais comuns aos membros da comunidade étnica portuguesa radicada no litoral do atual Estado do Paraná. Um destino consistia em pertencer ao núcleo de controladores do mercado de crédito local. Tal condição, por um lado, permitia ao português abastado reunir um séquito de dependentes. Por outro lado, ela favorecia o estritamento de ligações com negociantes de praças mercantis de maior porte, tais como o Rio de Janeiro. Os imigrantes enriquecidos exerciam, por exemplo, exerciam a função de cobradores de dívidas dos negociantes cariocas.

Dessa maneira, a partir dos anos 1810 a interação entre modestos e abastados negociantes das sociedades de Morretes e Paranaguá revestiu-se de um aspecto rotineiro. Tal aspecto era decorrente do fato de que o relacionamento entre esses dois setores da comunidade portuguesa era limitado ao âmbito da obtenção e renegociação de dívidas. Os percursos sociais de membros da família Vieira dos Santos apresentam-se como indícios de que o estabelecimento de relações familiares entre os integrantes de ambos os setores foi mais frequente até o início dos anos 1810, em um período no qual o desnível econômico entre eles era menos acentuado.

O filho mais novo de Antônio Vieira, José, também necessitou do auxílio econômico do português Antônio de Araújo para consolidar-se colo comerciante autônomo. Mais precisamente,

21 Ibid., p. 28. 
tal auxílio permitiu a José Vieira seguir a ocupação econômica exercia por seu pai. Houve, pois, a reiteração da dependência dos filhos do patriarca, o Antônio Vieira, para com os portugueses que desde os anos 1810 possuíam séquitos de devedores.

Os empréstimos dos controladores locais do mercado de crédito eram necessários para filhos de pequenos comerciantes iniciarem-se na atividade profissional exercida pelos seus ascendentes. Dessa forma, José Vieira dos Santos pôde inaugurar o seu armazém de bebidas, em Morretes, em virtude do auxílio pecuniário fornecido por Araújo. Nessa oportunidade, José Vieira contava 25 anos de idade. Respeitante a esse episódio, Antônio Vieira observou: "Quinta feira $1^{\circ}$ de tarde falei ao Alf ${ }^{\text {es }}$ Joze Antonio de $\mathrm{Ar}^{\mathrm{O}}$ $\mathrm{p}^{\mathrm{a}}$ dar cartas de abono a meu $\mathrm{f}^{\mathrm{o}}$ Joze Vieira e mandei buscar hua receita de molhados ao Rio de Janeiro q' a deu em 10 de Fever ${ }^{\circ} \mathrm{p}^{\mathrm{a}}$ Fran $^{\text {co }} X^{\text {er }}$ Dias da Fonseca". 22

De modo análogo ao caso de seu pai, José Vieira também demandava empréstimos na praça mercantil do Rio de Janeiro. Assim, ele também era interpelado por intermediários acerca do pagamento das dívidas contraídas na capital do Império. Em 1847, por exemplo, o citado Antônio de Araújo permanecia na função de intermediário dos negociantes cariocas que concediam empréstimos a comerciantes de áreas interioranas. Concernente à dívida de seu filho José para com um negociante carioca, Antônio Vieira destacou: "Em 8 Sabado escrevi a meu $\mathrm{f}^{\mathrm{o}}$ Joze sobre a divida que elle estava devendo ao Fran ${ }^{\mathrm{co}}$ $\mathrm{X}^{\mathrm{er}}$ Dias da Fonseca $\mathrm{p}^{\mathrm{r}}$ ter vindo hum caix ${ }^{\mathrm{ro}}$ do Rio de Janeiro a cobrança de dividas do $\mathrm{m}^{\mathrm{mo}}$ sugeito e o $\mathrm{S}^{\text {or }} \mathrm{Ar}^{\mathrm{o}}$ escreveo ao $\mathrm{m}^{\mathrm{mo}}$ meu filho a respeito". ${ }^{23}$

Nesse sentido, três décadas após intermediar o pagamento das dívidas de seu concunhado Antônio Vieira, Araújo conservava as suas ligações com comerciantes da cidade do Rio de Janeiro. Portanto, nesse ínterim não houve modificação nas relações de dependência de membros da família Vieira dos Santos com os membros abastados da comunidade étnica portuguesa de Morretes e desde o ano de 1838 [manuscrito], p. 3.

23 Ibid., p. 94. 
Paranaguá. A reiteração das formas de dominação exercidas por tais membros era um aspecto do poder econômico e prestígio social desses imigrantes na aludida localidade.

Uma aproximação entre Antônio Vieira e seu filho José recaia no fato de que eram economicamente dependentes de Antônio de Araújo. Nos anos 1840, o aprofundamento das dificuldades financeiras motivou Antônio Vieira a tornar-se empregado de seu compatrício. A análise das memórias desse imigrante possibilita afirmar que ele atuara como guarda-livros de Araújo. Porém, as animosidades existentes entre ambos inviabilizou a continuidade de Vieira como funcionário daquele negociante: "Em 7 Quarta de manhã perto do meio dia Araujo me dice certas palavras que $\mathrm{m}^{\text {to }}$ me escandalizarão. Fui falar com o Agostinho $\mathrm{p}^{\mathrm{a}}$ hir $\mathrm{p}^{\mathrm{a}}$ caza delle. Tornei entregar ao $\mathrm{Ar}^{\mathrm{o}}$ os $25 \$ 000 \mathrm{r}^{\mathrm{s}}$ q' me deu do mez de Junho junto com hum bilhete de despedida". ${ }^{24}$

De outra parte, a aproximação entre Antônio Vieira e seu filho primogênito decorria do fato de ambos possuírem, nos 1840, dívidas com o supracitado português Manuel Francisco Correia. Em 1847, por exemplo, Antônio Vieira destacou que Antônio Júnior pera um devedor de Manuel Correia: "Em 3 [de junho] Quinta $\mathrm{fr}^{\mathrm{a}}$ escreveu o Ten ${ }^{\mathrm{e}} \mathrm{Cor}^{\mathrm{el}}$ Manoel Fran ${ }^{\mathrm{co}} \mathrm{Corr}^{\mathrm{a}}$ hua carta a meu $\mathrm{f}^{\mathrm{o}}$ Antonio parece q' a resp $^{\text {to }}$ do q' elle deve. E no dia 12 outra carta". ${ }^{25}$ No ano seguinte, a dívida de Antônio Vieira, pai, com Manuel Correia despertou uma reação de Antônio Júnior e José Vieira: "Em 7 [de janeiro de 1848] Sesta $\mathrm{fr}^{\mathrm{a}}$ recebi cartas do $\mathrm{Ten}^{\mathrm{e}} \mathrm{Cor}^{\mathrm{el}} \mathrm{M}$. F. Corr ${ }^{\mathrm{a}}$ tendente a divida que lhe devo e meus filhos Antonio e Joze responderão a meu respeito oferecendose a trabalhar em beneficiar Ervas p ${ }^{a}$ elle" ${ }^{26}$

Dessa forma, tais informações consistem em evidências de que a manutenção de compatriotas - e de seus descendentes - em posição de sujeição econômica foi realizada por portugueses como Antônio de Araújo e de Manuel Correia. Ao longo das primeiras décadas do século XIX, eles forneceram créditos a antigos e novos imigrantes portugueses. Entretanto, o limite da relação entre esses 
fornecedores de crédito e seus compatrícios era de natureza econômica. $\mathrm{O}$ mercado matrimonial composto pelos ricos negociantes portugueses de Paranaguá, por exemplo, era vedado a imigrantes que, de forma semelhante a Antônio Vieira, não possuíam expressivo patrimônio. Cabe demonstrar, nos estágios seguintes deste artigo, que a hierarquização da comunidade portuguesa no litoral do atual Paraná criava uma situação na qual os pequenos comerciantes de Morretes e Paranaguá formavam um grupo onde se realizavam alianças familiares e comerciais.

\section{Reveses econômicos e migrações internas: elementos peculiares aos percursos de imigrantes portugueses $e$ seus descendentes em Morretes e Paranaguá}

No curso desta etapa do artigo é sustentado o argumento de que as migrações internas eram comumente realizadas por imigrantes portugueses que vivenciavam uma falência comercial ou que não dispunham dos recursos suficientes para permanecer no exercício de atividades como o tráfico de escravos. Assim, compete demonstrar que, na primeira metade do século XIX, distintos membros da família Vieira dos Santos realizaram migrações por províncias sulinas com a finalidade de reabilitarem-se como comerciantes. Assim, a consecução deste estágio do estudo permite evidenciar que a impossibilidade da quitação de dívidas apresentou-se como fator de desenraizamento social.

Por outro lado, é demonstrado que as migrações, no âmbito da família Vieira dos Santos, tiverem três efeitos: (I) permitir ao negociante falido atuar como representante comercial de negociantes abastados; (II) gerar o estabelecimento de alianças sociais, tais como o compadrio; (III) viabilizar a inserção do imigrante português no núcleo de comerciantes varejistas de uma localidade interiorana. Contudo, a aproximação entre esses três efeitos das migrações consiste no fato de que elas permitiram aos membros da citada 
parentela apenas acomodarem-se em posições subalternas na vida econômica de áreas interioranas de províncias do Sul do Brasil. Nesta seção a categoria de migração interna é aplicada em referência à movimentação de membros da referida família entre o litoral e o primeiro planalto do atual Estado do Paraná, bem como entre as províncias do Sul do Brasil.

O marco inicial desta seção do artigo é o ano de 1812. Nessa ocasião, um irmão de Antônio o comerciante varejista João Vieira dos Santos (1786-?) estava falido. Ele era irmão de Antônio Vieira. Por consequência, João Vieira evadiu-se de Paranaguá para não ser submetido às punições legais decorrentes do não pagamento das dívidas. Tal episódio é, pois, um caso conspícuo do desenraizamento social deflagrado pela dificuldade de pagamento de dívidas.

João Vieira era sócio de seu irmão Antônio de uma loja de secos e molhados localizada em Paranaguá. Contudo, João Vieira, em virtude de suas dívidas, optou por fugir desse município em virtude de sua falência. Esse imigrante não quitara débitos com a própria municipalidade de Paranaguá, cuja administração na época era exercida pela Câmara de Vereadores. Ao se evadir desse município, João Vieira migrou para a então Capitania do Rio Grande do Sul, onde atuou em ofícios como o de caixeiro. Assim, constata-se que, nas trajetórias dos irmãos Antônio e José Vieira dos Santos, a vivência de um revés comercial levou-os a exercer uma ocupação que haviam desempenhado no início de seus percursos sociais no Brasil. Em resumo, a falência comercial impeliu-os a decair na hierarquia do comércio, visto que caixeiragem era um ofício comumente destinado aos jovens que se iniciavam nas lides comerciais. ${ }^{27}$

27 Concernente às formas de absorção e treinamento de caixeiros no Brasil do princípio do século XIX, ver GORENSTEIN, Riva \& MARTINHO, Lenira. Negociantes e Caixeiros na Sociedade da Independência. Rio de Janeiro: Secretaria da Cultura, 1993. 
Em resumo, Antônio Vieira informou que, no Rio Grande do Sul, o seu irmão ocupou-se inicialmente da caixeiragem. Em seguida, envolveu-se no comércio do charque. Extraídas das memórias de Antônio Vieira, as informações apresentadas a seguir evidenciam que João Vieira, após a aludida falência, passou da condição de comerciante autônomo para a de empregado de comerciantes varejistas e de fazendeiros:

Em 21 ou 24 de Outubro de 1812 entrou meu Manno João na barra do Rio Grande com 21 a 24 dias de viagem e foi morar na $\mathrm{V}^{\mathrm{a}}$ do Norte em caza de Joze Lizandro da $\mathrm{S}^{\mathrm{a}}$ onde esteve 6 mezes ate o de Abril de 1813 sem ter arumação; porem $\mathrm{p}^{\mathrm{r}}$ Carta de 6 de Janr $^{\circ}$ de 1813 se ve elle estava ocupando a ser guarda da Alfandega onde esteve 3 mezes ate Março acontecendo-lhe hum um caxo na Sumaca Tarmelão obrigando-o largar desta ocupação pasandose depois $\mathrm{p}^{\mathrm{a}}$ a $\mathrm{V}^{\mathrm{a}}$ do Sul onde esteve de Caixr ${ }^{\mathrm{o}}$ de hua loge de botõens de João Alezandre Rosa somt ${ }^{\mathrm{e}} 20$ dias ganhando a meia dobla $\mathrm{p}^{\mathrm{r}}$ cada mez. Dali pasou $\mathrm{p}^{\mathrm{a}}$ a Freg $^{a}$ do Esp ${ }^{o}$ Santo no Cerrito da Lagoa do Jaguarão onde foi para Caixr ${ }^{\circ}$ de hum Armazem de molhados de Francisco do Canto o $\mathrm{q}^{1}$ era interessado com Antonio Ferr $^{\mathrm{a}}$ de Araujo de Piratenim ganhando 10 doblas $\mathrm{p}^{\mathrm{r}}$ anno em q' esteve só 10 mezes desde fins de Abril de 1813 ate $\mathrm{Fevr}^{\circ}$ de 1814, mas $\mathrm{p}^{\mathrm{r}}$ que ficou alcansado sahio do $\mathrm{m}^{\mathrm{mo}}$ Armazem indo $\mathrm{p}^{\mathrm{r}}$ Caixr $^{\mathrm{o}} \mathrm{p}^{\mathrm{a}}$ a Xarqueada do $\mathrm{Cap}^{\mathrm{m}}$ Joze $\mathrm{Ferr}^{\mathrm{a}}$ de $\mathrm{Ar}^{\mathrm{o}}$ interessado com outro Irmão Antonio Corr ${ }^{\mathrm{a}}$ de Araujo no rio de Piratenim ganhando $\mathrm{p}^{\mathrm{r}}$ anno 10 doblas $\mathrm{p}^{\mathrm{a}}$ pagar o alcanse q' teve com o Franc ${ }^{\circ}$ do Canto; esteve na da Xarqueada desde Março de 1814 ate $7^{\text {bro }}$ de 1815 na qual se achava a 22 mezes o q' não pode ser e só sim forão $19=$ mezes. $^{28}$

A partir dos anos 1820, Antônio Vieira não obteve novas informações sobre o destino de João Vieira. Contudo, as informações 
sobre o seu destino imediatamente após a referida fuga permitem salientar a sua acomodação em uma posição de subalternidade na vida econômica de uma província sulina. Por um lado, a realização de migração interna permitiu a João Vieira libertar-se dos seus credores. Por outro lado, ela impeliu-o retroceder na posição que havia conquistado na hierarquia das funções do comércio, pois João Vieira passara da condição de proprietário para a de funcionário de armazém de secos e molhados.

Um ano após a fuga de João Vieira, o seu irmão Antônio migrou de Paranaguá para a vila de Curitiba, situada no primeiro planalto do atual Paraná. Desde a década de 1800 o armazém de secos e molhados de Antônio Vieira em Paranaguá era deficitário. A sua transferência para Curitiba ocorreu, pois, em um contexto de aumento desses déficits. ${ }^{29}$ Esse imigrante permaneceu naquele município entre abril de 1813 e setembro de 1814. Em suas memórias, ele não forneceu informações pormenorizadas acerca das atividades econômicas que ali desempenhou.

Entretanto, as informações abaixo reproduzidas permitem destacar que Antônio Vieira buscou reabilitar-se em Curitiba como comerciante varejista. Mais especificamente, ele intentou se dedicar ao comércio de fazendas, isto é, de tecidos. A tentativa de manter-se como comerciante autônomo é também evidenciada pelo fato de que ele escolheu como local de residência a região mais central de Curitiba - a área em torno da Igreja Matriz. ${ }^{30}$ Leia-se, pois, a seguinte passagem do primeiro volume de sua obra memorialística:

Em 30 de Março de 1813 Terça $\mathrm{f}^{\mathrm{a}}$ de noite tomei a rezolução de hir com $\mathrm{m}^{\mathrm{a}}$ fazenda $\mathrm{p}^{\mathrm{a}}$ Coritiba e levei a medir e enfardar ate 7 de Abril. [...] Em 11 de Abril de

29 Para a análise sobre o agravamento da situação deficitária do armazém de Antônio Vieira, ver GOMES, Sandro Aramis Richter. Descentralização e pragmatismo: condições sociais de produção das memórias histórias de Antônio Vieira dos Santos. Dissertação (Mestrado em História). Curitiba: Universidade Federal do Paraná, 2012.

30 A respeito da organização espacial de Curitiba no início do século XIX, ver KATO, Allan Thomas Tadashi. Retrato Urbano. Estudo da distribuição socioespacial dos moradores de Paranaguá, Antonina e Curitiba no início do século XIX. Dissertação (Mestrado em História). Curitiba: Universidade Federal do Paraná, 2011. 
1813 Dom $^{\circ}$ pelas 2 horas da tarde sahi dos Morretes pa ${ }^{\mathrm{a}}$ $\mathrm{V}^{\mathrm{a}}$ de Cor $^{\mathrm{a}}$ indo pouzar na Prainha. Em 12 de Abril Segd ${ }^{\mathrm{a}}$ $\mathrm{f}^{\mathrm{a}}$ subimos a Serra de Coritiba e cahio para hum roçado 1 mula com 2 caixõens de ferragens indo pouzar no curral falso. Em 13 de Abril de 1813 Terça f $^{a}$ sahindo de pouzo entrei na Villa de Coritiba pelas 3 horas da tarde e fui morar nas Cazas de Manoel Doas da Costa no pateo da $\mathrm{Ig}^{\mathrm{ra}} \mathrm{N}^{\mathrm{o}} 36 .{ }^{31}$

Ao tempo de sua vivência em Curitiba, Antônio Vieira manteve relações sociais com membros da elite local. Os indivíduos com os quais ele interagiu nesse contexto eram detentores das principais patentes na Companhia de Milícias da localidade. Antônio Vieira estabeleceu relações de compadrio com personagens da elite curitibana.

Dentre esses personagens estava Inácio de Sá Souto Maior, Sargento-Mor da vila. Esse indivíduo foi o padrinho de crisma de um filho de Antônio Vieira, a saber, o citado José. Acerca do estabelecimento de relações de compadrio na época de sua permanência em Curitiba, Antônio Vieira dos Santos destacou que no dia 21 de setembro de 1813 " "[...] se crismou na $\operatorname{Igr}^{\mathrm{a}}$ da $\mathrm{V}^{\mathrm{a}}$ da Cor $^{\mathrm{a}}$

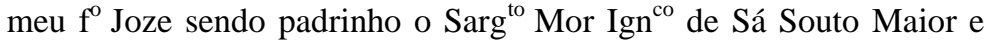
minha filha Anna, sendo Madr ${ }^{\mathrm{a}}$ D. M ${ }^{\mathrm{a}}$ Angélica de Sá e o Esc ${ }^{\mathrm{ro}} \mathrm{Fran}^{\mathrm{co}}$ de q' foi $\operatorname{padr}^{\circ}$ o Ten ${ }^{\mathrm{e}}$ Joaquim Joze Leite pelo $\mathrm{P}^{\mathrm{e}}$ vesitador Luiz Joze de Carvalho". ${ }^{32}$

Todavia, Antônio Vieira não prosperou como comerciante no planalto curitibano. Por conseguinte, empreendeu nova migração. Em fins de 1814, ele se transferiu para a então freguesia de Morretes, localidade na qual estavam enraizados os pais de sua esposa. A sua migração para Morretes era, pois, um indício de sua dependência para com os auxílios econômicos fornecidos pelos indivíduos da família Ferreira de Oliveira. Nesse quadro, Antônio Vieira instalou, em 1814, o seu comércio de ferragens em um imóvel de sua sogra: "Em 6 de

31 SANTOS, Antônio Vieira dos. Breve resumo... Op. cit., p. 17.

32 Ibid., p. 18. 
$8^{\text {bro }}$ de 1814 Quinta $\mathrm{f}^{\mathrm{a}}$ arrumei a $\mathrm{m}^{\mathrm{a}}$ fazenda com hum quarto na caza de $\mathrm{m}^{\mathrm{a}}$ Sogra $\mathrm{N}^{\mathrm{o}} 52^{\prime}{ }^{33}$

Na década seguinte, a realização de migração interna foi realizada por um imigrante português que ingressou ao grupo familiar dos Vieira dos Santos. Tal informação permite salientar que, no âmbito da sociedade do litoral do atual Paraná, havia a tendência de pequenos comerciantes portugueses consolidarem estreitas relações econômicas e familiares. A aproximação entre esses imigrantes também residia no fato de que experimentaram multifacetadas adversidades na execução de seus intentos comerciais. Eles eram próximos, ainda, pelo fato de pertencerem ao séquito de devedores de negociantes de origem portuguesa radicados naquela região.

O imigrante português incorporado ao grupo familiar dos Vieira dos Santos nos anos 1830 era José Lopes Ferreira (1797-1836). No princípio de sua trajetória no Brasil, ele atuara como traficante de escravos. Porém, não possuía os recursos suficientes para dedicar-se com regularidade a tal comércio. Em seguida, foi comerciante varejista em Morretes e negociante de tropas de animais de carga. As informações apresentadas a seguir evidenciam que a migração da cidade do Rio de Janeiro para o litoral sul paulista foi a estratégia encontrada por José Lopes para se consolidar como comerciante autônomo:

Verificouse o estado delle no Rio de Janeiro de 5 a 6 mezes pellos papeis da compra q' fes dos $\operatorname{Escr}^{\mathrm{os}} \mathrm{p}^{\mathrm{r}} \mathrm{q}$ ' em 28 de Agosto de 1830 comprou o escr ${ }^{\circ}$ Antônio $\mathrm{p}^{\mathrm{r}}$ $540 \$ 000 \mathrm{r}^{\mathrm{s}}$ a Manoel Fran ${ }^{\mathrm{co}}$ Coelho; e em 7 de Dezembro do $\mathrm{m}^{\mathrm{mo}}$ anno comprou o escr ${ }^{\circ}$ Joze Congo ao seu Socio

33 Ibid., p. 20. 
Manoel Joze Pereira Bastos. Pode ser depois do dia 9 de Dezembro sahise do Rio de Janeiro e chegase a Paranagua com a viagem breve, e logo fosse Antonina e viese com Antônio Joze Ov ${ }^{\text {a }}$ Ramos rumo aos Morretes. ${ }^{34}$

Em resumo, José Lopes pertencia à categoria de imigrantes desprovidos do capital necessário para dedicar-se a atividades econômicas de vulto em relevantes praças mercantis. Assim, restou a ele a alternativa de transferir-se para uma pequena sociedade do litoral sul paulista e vincular-se à família de um compatrício que também vivenciava dificuldades para a consecução de seus projetos econômicos. Estabelecido em Morretes, Lopes pertenceu ao séquito de negociantes portugueses como o citado Manuel Francisco Correia. A tentativa de diversificar os seus negócios por meio da participação no comércio de tropas exigiu, por exemplo, a obtenção de um empréstimo de Correia. ${ }^{35}$ Assim, a inserção de Lopes na sociedade de Morretes, nos anos 1830, evidencia o caráter segmentado da comunidade étnica portuguesa formada no sul do litoral da Província de São Paulo. Assim, os modestos comerciantes eram inclinados a estabelecer alianças familiares e econômicas, ao passo que mantinham relações essencialmente contratuais com os patrícios enriquecidos. Conforme salientado, essas relações contratuais referiam-se à obtenção e negociação de empréstimos.

$* * *$

Compete salientar que, nos anos 1840 , a realização de migração interna foi peculiar ao percurso de um filho de Antônio Vieira dos Santos, a saber, José Vieira. Ele migrou de Morretes para o planalto curitibano, na região da Borda do Campo. Nesse contexto, o 
seu objetivo era dedicar-se ao comércio de erva-mate. Por um lado, cabe destacar que a migração para o planalto era um indício de que os Vieira dos Santos possuíam ligações com membros da elite social dessa região. Assim, é necessário destacar que José Vieira era casado com Emília Sofia Borba, filha de Vicente Antônio Morocine Borba, que detinha a patente de Capitão de Milícias de Curitiba. Por outro lado, a migração não permitiu a Antônio Vieira, nos anos 1810, e a José Vieira, nos anos 1840, prosperar nos negócios. Assim, o retorno para o litoral foi o destino comum de ambos.

Referente a reminiscências do ano de 1847, Antônio Vieira ressaltou que seu filho José tinha por objetivo desligar-se do engenho na Borda do Campo e retornar para Morretes: "Em 4 Sesta o Maneco dos $\mathrm{S}^{\text {tos }} \operatorname{Cordr}^{\mathrm{o}}$ parece esteve consultando com $\mathrm{Ar}^{\mathrm{o}}$ a respt $^{\mathrm{o}}$ de meu $\mathrm{f}^{\mathrm{o}}$ Joze estar desacorsoado e não querer fazer mais o $\operatorname{Eng}^{\circ}$ na borda do Campo, estando resolvido mudar $\mathrm{p}^{\mathrm{a}}$ aqui". ${ }^{36}$ Contudo, cabe salientar que o malogro das atividades comerciais de José Vieira também foi ocasionado de seus problemas de saúde. Adoecido, José Vieira retornou a Morretes, onde faleceu, em 1850.

Nas memórias de Antônio Vieira, portanto, aos problemas de saúde de José Vieira é o fator que justificam o seu retorno à casa paterna. Assim, no caso desse indivíduo não há informações que permitam assegurar que tal retorno foi decorrente de dificuldades no desenvolvimento de seus negócios. Em novembro de 1848, por exemplo, Antônio Vieira registrou: "Em 21 Terça a meia noite deste dia ao amanhecer a 22 teve meu $\mathrm{f}^{\circ}$ Joze hum ataque repentino apopletico estando dormindo com sua Espoza e filhas e se não fosse o Borba estar acordado certamt ${ }^{\mathrm{e}}$ morreria".

Dessa forma, os comerciantes pertencentes à família Vieira dos Santos pareciam encarar a migração como estratégia adequada para a recuperação de um revés econômico. Tal situação foi peculiar aos casos de Antônio e João Vieira dos Santos e também de José Lopes Ferreira. Por fim, a migração era um indício de que pequenos comerciantes possuíam conexões sociais para além da localidade na qual estavam enraizados. A inserção de José Vieira dos Santos na 
sociedade do planalto curitibano permite, pois, corroborar tal assertiva.

\section{Mercado matrimonial, compadrio e hierarquia: $o$ perfil social de compadres e genros de Antônio Vieira dos Santos}

Nesta etapa do artigo é sustentado o argumento segundo o qual, entre as décadas de 1800 e 1840, não houve uma expressiva mudança no perfil social dos compadres de Antônio Vieira dos Santos. De outra parte, é demonstrado que os genros desse imigrante, nos anos 1830 e 1840, enquadravam-se na categoria de pequenos comerciantes portugueses. Nesse contexto, os pequenos comerciantes eram distantes dos seus compatriotas enriquecidos tanto em virtude do desnível econômico quanto em decorrência de participarem de distintos mercados matrimoniais. Em resumo, a consecução deste estágio da análise possibilita evidenciar o aspecto hierarquizado da comunidade portuguesa no litoral do atual Estado do Paraná, na primeira metade do século XIX.

$* * *$

Antes de pertencer aos séquitos de credores de Manuel Francisco Correia e Antônio José de Araújo, Antônio Vieira dos Santos estabeleceu com eles relações de compadrio. Ao mesmo tempo, ele também era compadre de Manuel Antônio Pereira, um dos principais intermediários, em Paranaguá, dos credores estabelecidos no Rio de Janeiro. Manuel Pereira foi o padrinho de batismo de Ana 
Joaquina de Oliveira França, em 1809. ${ }^{38}$ Manuel Correia foi o padrinho de crisma de Maria Cândida Vieira dos Santos, em 1809. ${ }^{39}$ Antônio José de Araújo, por sua vez, foi padrinho de batismo de José Vieira dos Santos, em 1813. ${ }^{40}$

Nessa época, esses negociantes aproximavam-se pelo fato de que pertenciam à condição de comerciantes que haviam abandonado há poucos anos a condição de caixeiro. Esses indivíduos, portanto, vivenciaram um análogo processo de integração na sociedade do litoral sul da então Capitania de São Paulo. Em síntese, esse processo consistia em ser acolhido por um compatriota, obter desse patrício um treinamento na vida mercantil e participar do mercado matrimonial formado por descendentes de portugueses. Entretanto, episódios como a falência comercial minaram as chances de Antônio Vieira dos Santos ascender à categoria dos imigrantes que controlavam o mercado de crédito, comandavam as instituições políticas locais e possuíam os recursos necessários para diversificar os seus negócios. Nessa época, os enriquecidos imigrantes portugueses de Paranaguá investiam, por exemplo, na aquisição de imóveis com a finalidade de tornarem-se rentistas urbanos. ${ }^{41}$

Por consequência, a diferenciação econômica entre esses compatrícios impôs limites às suas relações sociais. A partir dos anos 1810, essas relações eram limitadas a um âmbito contratual - a concessão e renegociação de dívidas. Nas décadas seguintes, os compadres e genros de Antônio Vieira eram modestos comerciantes de origem portuguesa. Para a fundamentação deste argumento, é necessário dedicar atenção às ocasiões em que Ana Joaquina de Oliveira França contraiu matrimônio.

O seu primeiro matrimônio foi realizado em 1831, com o citado José Lopes Ferreira. ${ }^{42}$ Assim, Ana Joaquina tornara-se esposa de um português que migrara para o litoral sul da Província de São Paulo em virtude do insucesso da tentativa de manter-se na capital do

38 SANTOS, Antônio Vieira dos. Breve resumo... Op. cit., p. 14.

39 Ibid., p. 11.

40 Ibid., p. 111.

41 Acerca dos aspectos da riqueza de imigrantes portugueses que pertenceram à geração de Antônio Vieira dos Santos, ver CAVAZZANI, André Luiz Moscaleski. Tendo o sol por testemunha... Op. cit.

42 SANTOS, Antônio Vieira dos. Memórias dos sucessos... Op. cit., p. 428-429. 
Império como um traficante de escravos. Ou seja, trata-se de um casamento celebrado entre a filha de um negociante sobremodo endividado com um imigrante que, aos 34 anos de idade, ainda não conseguira se afirmar em qualquer ramo da vida mercantil.

Ana Joaquina tornou-se viúva em 1836. Em 1838, José Mariano Vargas, mestre de embarcação, manifestou a Antônio Vieira o interesse de desposar Ana Joaquina. Assim, verifica-se que o pretendente também não pertencia às elites dos municípios do litoral sul paulista. Nessa ocasião, Antônio Vieira ditou o ritmo das conversações sobre o matrimônio.

Em decorrência do modo vagaroso como transcorriam essas conversações, Vargas desistiu do intento nupcial. Assim, o pretendente de Ana Joaquina não possuía qualquer ligação com as sociedades litorâneas de Morretes e Paranaguá. Trata-se, pois, de um indício de que eram os imigrantes recém-chegados, despossuídos de vultoso capital, e os frequentadores ocasionais do porto de Paranaguá os indivíduos que faziam parte do mercado matrimonial composto por membros da família Vieira dos Santos. Acerca das conversações entre Antônio Vieira e José Mariano Vargas, atente-se ao seguinte fragmento da obra do memorialista:

Segunda feira 23 andei despachando na Alfandega os generos de molhados que vierão do Rio de $\operatorname{Janer}^{\circ}$ no B. Duas Irmãns $\mathrm{p}^{\mathrm{a}}$ meu filho Joze; e foi a $\mathrm{pr}^{\mathrm{a}}$ ves que conheci e falei com o Mestre do $\mathrm{m}^{\mathrm{mo}}$ B. Joze Mariano de Vargas. [...] Em Quarta $\mathrm{fr}^{\mathrm{a}} 2$ de tarde parece que chegou aos Morretes o Joze Mariano de Vargas $\mathrm{M}^{\mathrm{e}}$ do B. Duas Irmãns vindo a pedir em cazam ${ }^{\text {to }} \mathrm{a} \mathrm{m}^{\mathrm{a}} \mathrm{f}^{\mathrm{a}}$ Anna Vieira $\mathrm{p}^{\mathrm{r}}$ persuaçõens de F. Roiz e outros passageiros q' forão com elle ao Rio de Janeiro; cuja noticia sube $\mathrm{p}^{\mathrm{r}}$ elles em 16 ou 17 de Abril depois q' chegarão aos Morretes. Quinta fr ${ }^{\mathrm{a}} 3$ de tarde veio recado $\mathrm{p}^{\mathrm{r}}$ via de F. R. a $\mathrm{m}^{\mathrm{a}} \mathrm{f}^{\mathrm{a}}$ o peditorio do mesmo sug ${ }^{\text {to }}$. Sabado 5 de tarde veio pessoalmente pedir o dito F. Roiz em nome do tal. De noite mandei-o chamar e lhe dei reposta não deciziva. Domingo 6 de manhã veio em $\mathrm{m}^{\mathrm{a}}$ caza o tal Joze Mariano de Vargas e com elle falei 
pessoalmente sobre o mesmo objecto sem resposta definitiva e elle de tarde se foi embora. ${ }^{43}$

Em 1843, contudo, Ana Joaquina contraiu núpcias com o português Agostinho José Pereira de Lima, que tinha à época a idade de 27 anos. $^{44}$ Ele transferiu-se para o Brasil em 1836. Atuou como caixeiro no Rio de Janeiro durante cinco anos (1836-1841). A sua inserção na sociedade de Morretes ocorreu em 1841, quando se tornou sócio de Manoel Francisco Correia Júnior (1809-1857) no comércio de fazendas. Correia Júnior era filho do citado imigrante que controlava o mercado de crédito em Paraná. A respeito dessa sociedade, Antônio Vieira dos Santos informou:

Em 9 ou 10 de Setembro deste anno [1841] veio o Agostinho Joze Per $^{\mathrm{a}}$ Lima com negocio de fazenda, interessado com o $\mathrm{Co}^{\text {rel }} \mathrm{M}^{\mathrm{el}} \mathrm{Fran}^{\mathrm{co}} \mathrm{Corr}^{\mathrm{a}} \mathrm{J}^{\text {or }}$, e aqui nesta $\mathrm{V}^{\mathrm{a}}$ dos Morretes estabeleceo a sua moradia. O papel da Socie $^{\text {de }}$ tem dacta de 10 de $9^{\text {bro }}$ e $\mathrm{p}^{\text {ra }}$ receita em 15 de $7^{\text {bro }}$. O capital da Socied e q' aturou té 5 de $7^{\text {bro }}$ de 1843 foi da $\mathrm{q}^{\text {ta }}$ de 4:919\$377 $\mathrm{r}^{\mathrm{s}}$.

Assim, ao longo da primeira metade do século XIX, a região do litoral do atual Paraná continuou a receber imigrantes. Porém, nota-se que nesse contexto alguns dos recém-chegados já possuíam o treinamento na vida mercantil. $O$ ingresso naquela localidade era decorrente, por exemplo, da tentativa de recomeçar as atividades econômicas ou da faculdade de estabelecer uma sociedade comercial.

Porém, esses imigrantes não angariaram a oportunidade de se aproximar de negociantes portugueses mais abastados. Trata-se, pois, de uma diferença em relação ao contexto imigratório do fim do século XVIII. Assim, o caso das núpcias de Ana Joaquina evidencia que, a 
partir dos anos 1830, Antônio Vieira atuou como o imigrante que incorporou pequenos comerciantes varejistas à sua família. Os pequenos comerciantes de origem portuguesa, assim, formavam uma comunidade na qual eram realizadas alianças econômicas e sociais.

$* * *$

Nos anos 1840, verificou-se o caráter endógeno das relações de compadrio de Antônio Vieira. Assim, ele se tornou compadre, por exemplo, de um de seus genros. Estes, por sua vez, não recrutavam os padrinhos de seus filhos no interior da elite econômica de Morretes e Paranaguá. A hierarquização da comunidade portuguesa na aludida região implicava restrições à diversificação do perfil social dos padrinhos de pequenos comerciantes. Assim, cabe mencionar que, em 1847, Agostinho, filho de Ana Joaquina e Agostinho Pereira, foi batizado pelo avô materno, Antônio Vieira dos Santos, e pela tia materna, Maria Cândida Vieira dos Santos. Por outro lado, Agostinho Pereira era compadre de seu cunhado Antônio Vieira dos Santos Júnior. Em 1850, Agostinho Pereira batizou Frederico, filho de Antônio Júnior. ${ }^{46}$

\section{Considerações finais}

A principal finalidade deste artigo consistiu na produção de um conhecimento sobre as desigualdades econômicas e sociais que existiram entre os membros da comunidade de imigrantes portugueses estabelecida no litoral do atual Estado do Paraná, na primeira metade do século XIX. Assim, buscou-se evidenciar, por meio do caso da 
família Vieira dos Santos, a reiteração, de uma geração a outra, das formas de dominação social internas àquela comunidade portuguesa.

Primeiro, destacou-se que a ausência de alternativas para o financiamento de iniciativas econômicas exigia dos pequenos comerciantes portugueses, naquela região, a busca pelo crédito privado. Os controladores do mercado de crédito local eram portugueses ali radicados desde o fim do século XVIII. Esses negociantes também atuavam como intermediários dos credores de importantes praças mercantis, tais como o Rio de Janeiro. Os pequenos comerciantes, a exemplo de Antônio Vieira e seus filhos, permaneciam durante anos na condição de integrantes dos séquitos de devedores desses abastados negociantes portugueses. As mais frequentes relações entre os imigrantes economicamente desiguais ocorriam nas negociações dos contratos de crédito.

Segundo, foi demonstrado que a realização de migrações internas foi um elemento comum aos percursos de membros de distintas gerações da família Vieira dos Santos. Essas migrações apresentavam-se como uma estratégia destinada a possibilitar o soerguimento econômico do comerciante falido. Porém, notou-se que a migração realizada por Antônio Vieira não foi operacional para ele se consolidar como um comerciante autônomo. Antes, ele precisou retornar ao litoral e recorrer aos auxílios pecuniários de parentes de sua esposa para reabilitar-se como comerciante. João Vieira, por seu turno, experimentou o retrocesso na sua posição na hierarquia da vida comercial após migrar para o Rio Grande do Sul. Porém, as migrações permitiam a ampliação de relações sociais. Tal ampliação foi peculiar aos casos de Antônio Vieira e seu filho.

Terceiro, a família Vieira dos Santos incorporava pequenos comerciantes portugueses. Nos anos 1840, tornou-se mais evidente a segmentação da comunidade portuguesa nas sociedades de Morretes e Paranaguá. De um lado, estavam os abastados negociantes, próximos em virtude do poder econômico e relações familiares. De outro lado, estavam os pequenos comerciantes, cuja aproximação decorria da vivência de análogas dificuldades econômicas e da constituição de alianças familiares.

RECEBIDO EM: 25/07/2016

APROVADO EM: 13/06/2017 